\title{
Growth and morphological analysis of segmented AuAg alloy nanowires created by pulsed electrodeposition in ion-track etched membranes
}

\author{
Ina Schubert ${ }^{*}$, Loic Burr ${ }^{1,2}$, Christina Trautmann ${ }^{1,2}$ and Maria Eugenia Toimil-Molares ${ }^{1}$
}

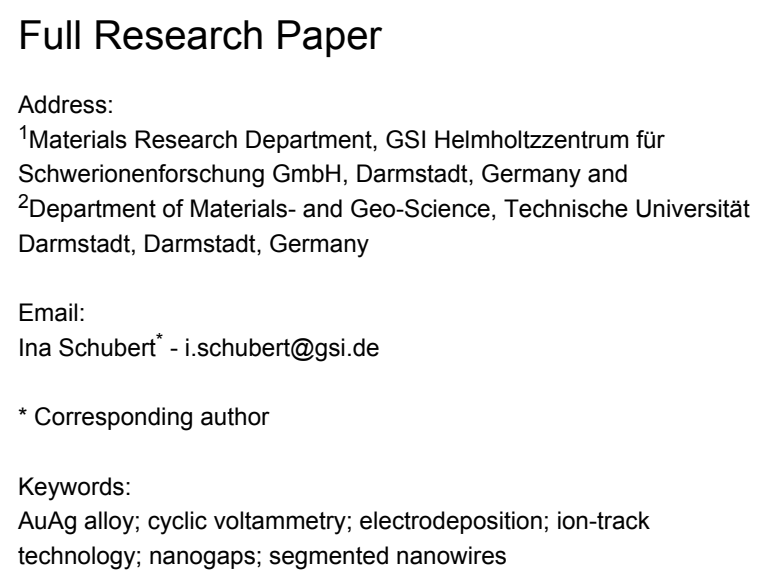

Beilstein J. Nanotechnol. 2015, 6, 1272-1280.

doi:10.3762/bjnano.6.131

Received: 10 February 2015

Accepted: 11 May 2015

Published: 08 June 2015

Associate Editor: P. Ziemann

() 2015 Schubert et al; licensee Beilstein-Institut. License and terms: see end of document.

\begin{abstract}
Background: Multicomponent heterostructure nanowires and nanogaps are of great interest for applications in sensorics. Pulsed electrodeposition in ion-track etched polymer templates is a suitable method to synthesise segmented nanowires with segments consisting of two different types of materials. For a well-controlled synthesis process, detailed analysis of the deposition parameters and the size-distribution of the segmented wires is crucial.

Results: The fabrication of electrodeposited AuAg alloy nanowires and segmented Au-rich/Ag-rich/Au-rich nanowires with controlled composition and segment length in ion-track etched polymer templates was developed. Detailed analysis by cyclic voltammetry in ion-track membranes, energy-dispersive X-ray spectroscopy and scanning electron microscopy was performed to determine the dependency between the chosen potential and the segment composition. Additionally, we have dissolved the middle Ag-rich segments in order to create small nanogaps with controlled gap sizes. Annealing of the created structures allows us to influence their morphology.
\end{abstract}

Conclusion: AuAg alloy nanowires, segmented wires and nanogaps with controlled composition and size can be synthesised by electrodeposition in membranes, and are ideal model systems for investigation of surface plasmons.

\section{Introduction}

The synthesis of multicomponent heterostructure nanowires is currently being intensively investigated. It has become evident that the combination of several materials in one nanostructure gives rise to specific functionalities that are not exhibited by the individual single components [1-4]. Different types of heterostructures such as core-shell, axially segmented or alloy nano- 
wires are being developed and characterized. Their applications in the fields of optics [5-8], magnetism [9,10], electronics $[11,12]$ and solar harvesting [13-15] are envisaged. The functionality of the multicomponent nanostructures is determined by their properties including composition, dimension, and crystallinity. Therefore, to develop synthesis methods that guarantee a precise control of these properties is important.

A powerful technique to synthesise nanowires with well-controlled morphological and crystallographic characteristics is the so-called template method [16,17]. A large number of wires up to $10^{10} \mathrm{~cm}^{-2}$ can be grown simultaneously. In particular, in the case of polymer templates created by ion irradiation and chemical track-etching, nanowires with various shapes such as cylindrical, conical and biconical, with lengths between 1 and 100 $\mu \mathrm{m}$, and diameters as small as about $15 \mathrm{~nm}$ can be fabricated [18]. By choosing different types of polymer membranes the surface morphology of the nanowires can be varied $[19,20]$. Since the successful growth of $\mathrm{Cu} / \mathrm{Co}$ and $\mathrm{Ni} / \mathrm{Cu}$ multilayer nanowires back in the 1990s [1,2,21], the template method has allowed for the growth of many different segmented structures combining polymers, semiconductors, and metals, such as $\mathrm{Au}-\mathrm{TiO}_{2}$ [11], $\mathrm{Au}$-polypyrrole [22], $\mathrm{Cu}-\mathrm{Se}$ [23], and $\mathrm{Au}-\mathrm{Co}$ [24]. While segmented nanowires can be grown by sequential exchange of the electrolyte $[8,25,26]$, it is also possible to use a single electrolyte and control the composition of the segments by tuning reduction potential and electrolyte composition [27$30]$. The segment lengths are adjusted by the amplitude and length of the applied pulse [27,30,31]. Being able to fabricate a very large amount of wires with excellent control over segment length is crucial for many applications $[28,30,32,33]$.

AuAg nanowires are particularly investigated in the fields of optics and electronics. Bimetallic AuAg nanowires are very promising as sensing tools for surface enhanced Raman spectroscopy [34]. As an example, AuAg alloy nanorods show enhanced sensing resolution compared to pure Au nanowires [35] while Au@Ag core shell nanorods allow to adjust the resonance frequency by varying the shell thickness [36]. Furthermore, optical applications include the readout of striping patterns in AuAg segmented nanowires via optical brightfield microscopy [37] and fluorescence spectroscopy for bioanalysis, such as biological multiplexing [7]. Finally, by etching one elemental type of segments in metallic barcoded wires, small gaps separating the unetched (remaining) segments are being created [38-40], which could find applications as hot spots for surface enhanced Raman spectroscopy [38,41-43] and for biosensing [44]. Furthermore, such gaps with precisely controlled dimensions allow for the systematic investigation of multipole surface plasmon modes $[39,45,46]$. Because of their high electrical conductivity [47], Au and Ag metallic wires have also great potential as electronic components [7] and, thus, Au nanowires separated by small gaps are very promising as nanowire electrodes that can be used as field effect transistors [48] and for the capture and electrical characterization of nanoparticles [49]. For all these applications, the length of the segments plays a determining role and, thus, the length distribution achieved during the simultaneous growth of nanowire arrays should be analysed and discussed in detail.

In this work, we synthesise segmented AuAg alloy nanowires by pulsed electrodeposition in track-etched membranes using a single electrolyte. In particular, we aim at controlling all segment sizes. We analyze the segment size distribution in detail and discuss the deposition conditions needed to fabricate very small nanogaps by subsequent etching of the middle Ag-rich segments in nitric acid. We apply cyclic voltammetry and analyze the deposition process in the channels of ion-track etched membranes compared to cyclic voltammetry for macroelectrodes.

\section{Experimental}

Polycarbonate foils (Makrofol N, Bayer AG) with a thickness of $30 \mu \mathrm{m}$ were irradiated with $\mathrm{Au}$ ions (ca. $2 \mathrm{GeV}$ ) at the linear accelerator UNILAC at GSI Helmholtzzentrum für Schwerionenforschung. Each ion crossing the foil creates a damage trail, the so-called ion track. A fluence of $10^{9}$ ions per $\mathrm{cm}^{2}$ was applied. By chemical etching, the damaged material is selectively dissolved converting the track into an open nanochannel [50]. The etching time controls the diameter of the resulting pores. Here, the irradiated foils were etched for $5 \mathrm{~min}$ in a $6 \mathrm{M} \mathrm{NaOH}$ solution at $50{ }^{\circ} \mathrm{C}$ to fabricate channels with diameters of about $110 \mathrm{~nm}$. A low resolution and a high resolution SEM image of such an ion-track etched membrane are depicted in Figure S1 of Supporting Information File 1.

In a next step, a Au layer was sputtered on one side of the polymer template, serving as the cathode for the deposition. It was reinforced with $\mathrm{Cu}$, electrodeposited at room temperature in a two electrode set-up at a potential of $-0.5 \mathrm{~V}$ between the $\mathrm{Cu}$ anode and cathode. The electrodeposition of nanowires in the pores of the template was performed in a three-electrode setup using a potentiostat (GAMRY Instruments, Reference $600 \mathrm{TM}$ ) and a platinum wire as counter electrode. All potentials given here are reported versus the reference electrode, being $\mathrm{Ag} / \mathrm{AgCl}$ (sat. $\mathrm{KCl}$ ). Before starting the deposition, the electrolyte in the electrochemical cell was preheated to $60{ }^{\circ} \mathrm{C}$. For wire deposition and cyclic voltammetry, we used basic cyanide electrolytes $(\mathrm{pH} \mathrm{13})$. They contain $0.25 \mathrm{M} \mathrm{Na}_{2} \mathrm{CO}_{3}$ ( $>99.8 \%$, Carl Roth), and $\mathrm{KAu}(\mathrm{CN})_{2}$ (Carl Roth) and $\mathrm{KAg}(\mathrm{CN})_{2}$ (Sigma Aldrich) in different concentrations as given in the results and discussion section [51]. 
Cyclic voltammograms (CVs) were recorded applying a scan rate of $30 \mathrm{mV} / \mathrm{s}$ and a step size of $5 \mathrm{mV}$. Counter electrode and reference electrode are the same as given above. The geometric area of the membrane used for deposition and the CVs was about $0.5 \mathrm{~cm}^{2}$, which corresponds to an effective electrode area of about $0.05 \mathrm{~cm}^{2}$ (ca. $10 \%$ porosity). For comparison, $\mathrm{CVs}$ were also recorded using a Au macroelectrode, having an electroactive area of $0.4 \mathrm{~cm}^{2}$.

Morphological analysis was performed using a field emission scanning electron microscope (SEM) (Jeol JSM 7401 F). Energy-dispersive X-ray (EDX) spectra were recorded in the SEM using a Bruker spectrometer applying an acceleration voltage of $20 \mathrm{kV}$ and analysed by a built-in software (Quantax). $\mathrm{Cu}$ TEM grids (Plano $\mathrm{GmbH}$ ) served as substrates.

\section{Results and Discussion}

To synthesise segmented AuAg alloy nanowires by pulsed electrodeposition using a single-bath electrolyte, we studied electrolyte and voltage characteristics by cyclic voltammetry. Figure 1a shows a CV of an electrolyte containing $50 \mathrm{mM} \mathrm{KAu}(\mathrm{CN})_{2}$ (blue line) and a second one of an electrolyte containing $50 \mathrm{mM} \mathrm{KAg}(\mathrm{CN})_{2}$ (red line). In addition, also the curve of a solution containing only $0.25 \mathrm{M} \mathrm{Na}_{2} \mathrm{CO}_{3}$ (black line) was measured. In all cases a Au rod served as working electrode. This Au rod is chosen, since also during nanowire deposition, we use a Au layer of sputtered $\mathrm{Au}$ on the membrane rear side as working electrode. During the process, the voltage is ramped from -0.1 to $-1.5 \mathrm{~V}$ and the current flowing in the cell is recorded. When approaching $-1.5 \mathrm{~V}$ the ramping is inverted.

As expected the black curve does not reveal any characteristic peaks. The strong current increase at high negative potentials, which can also be seen in the red and the blue curve, is assigned to hydrogen evolution. The blue and the red $\mathrm{CVs}$ reveal that the current onset for the reduction of $\operatorname{Ag}(\mathrm{CN})_{2}^{-}$ions is initiated at potentials closer to $0 \mathrm{~V}$ than for the $\mathrm{Au}(\mathrm{CN})_{2}^{-}$ions (Figure 1a). Accordingly, the reduction peak, indicating diffusion limited deposition, for the Au electrolyte is approached at $-1.4 \mathrm{~V}$. In the $\mathrm{CV}$ of the Ag electrolyte a peak at lower (less negative) potential of $-1.1 \mathrm{~V}$ can be seen. While the equilibrium potential for $\mathrm{Au}^{+} / \mathrm{Au}$ is more positive than for $\mathrm{Ag}^{+} / \mathrm{Ag}$, it is known that the equilibrium potential for the $\operatorname{Ag}(\mathrm{CN})_{2}^{-} / \mathrm{Ag}$ couple is more positive than that of the $\mathrm{Au}(\mathrm{CN})_{2}^{-} / \mathrm{Ag}$ couple [51]. Thus, it is possible that $\mathrm{Au}$ atoms from the $\mathrm{Au}$ working electrode are oxidised during the preheating to $60{ }^{\circ} \mathrm{C}$ for $30 \mathrm{~min}$ and displaced by Ag. Therefore, the reduction peak in the $\mathrm{CV}$ of the Ag electrolyte might result not only from Ag deposition but also from $\mathrm{Au}$ deposition. For the blue curve corresponding to the $\mathrm{Au}$ electrolyte an additional plateau is found at around $-0.75 \mathrm{~V}$,
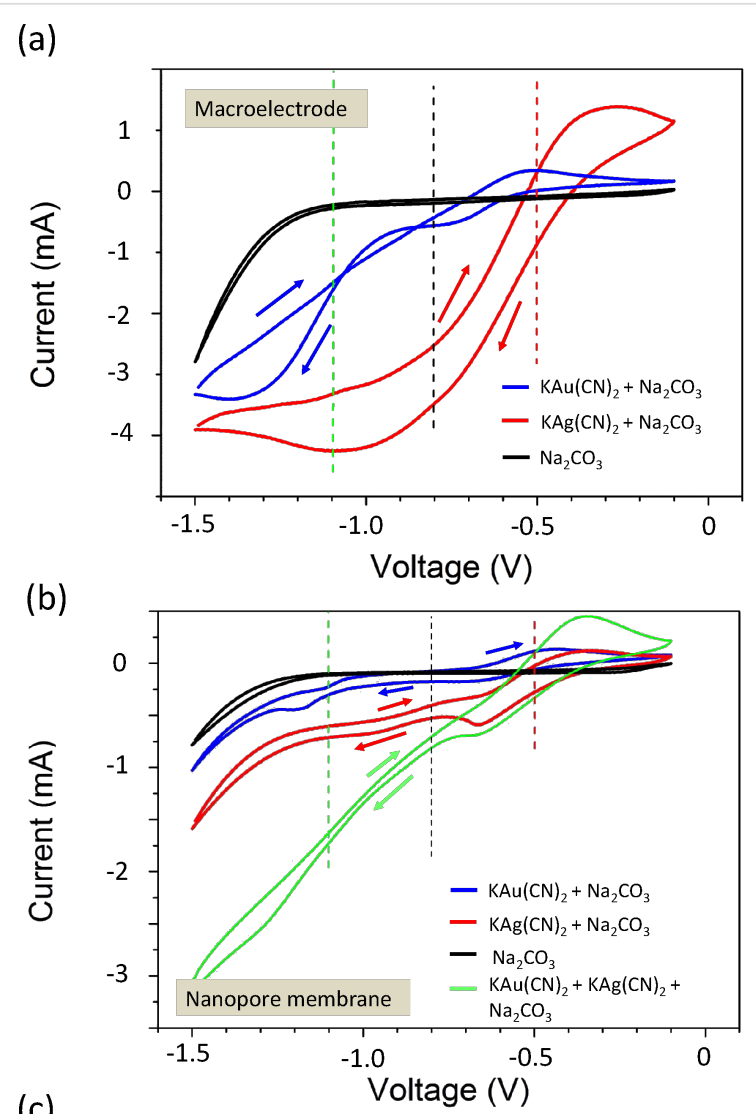

(c)

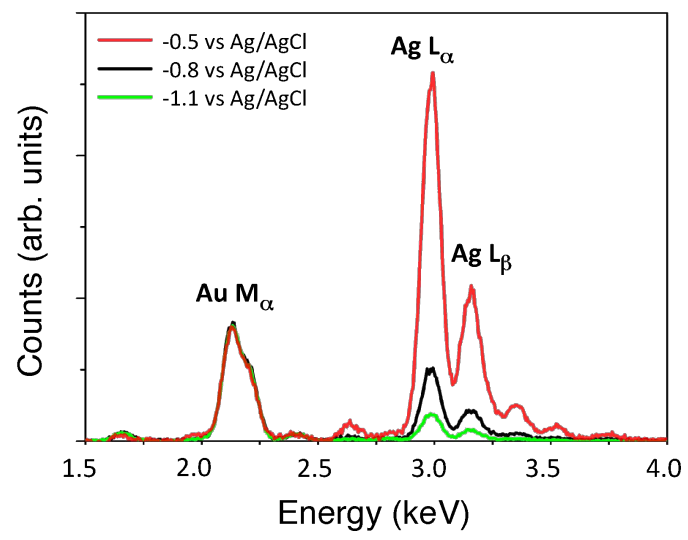

Figure 1: $\mathrm{CVs}$ using an electrolyte containing $50 \mathrm{mM} \mathrm{KAu}(\mathrm{CN})_{2}$ (blue line), an electrolyte containing $50 \mathrm{mM} \mathrm{KAg}(\mathrm{CN})_{2}$ (red line) and a solution containing only $0.25 \mathrm{M} \mathrm{Na}_{2} \mathrm{CO}_{3}$ (black line) using as working electrode (a) a gold wire and (b) a nanopore membrane with $10^{9}$ pores $/ \mathrm{cm}^{2}$ and sputtered Au on the bottom membrane side. The green curve in Figure $1 \mathrm{~b}$ corresponds to a solution containing $50 \mathrm{mM} \mathrm{KAuCN}_{2}$ and $20 \mathrm{mM} \mathrm{KAgCN}_{2}$. (c) Three representative EDX spectra of bundles of nanowires corresponding to different arrays deposited at $-0.5 \mathrm{~V}$ (red line), $-0.8 \mathrm{~V}$ (black line), and $-1.1 \mathrm{~V}$ (green line). The spectra are normalized to the energy of the Au Ma peak.

which is assigned to a different deposition route of $\mathrm{Au}(\mathrm{CN})_{2}^{-}$ ions. While in the diffusion-limited regime direct reduction of the $\mathrm{Au}(\mathrm{CN})_{2}^{-}$ions occurs, it is known that at small overpotentials the deposition of $\mathrm{Au}$ proceeds through the absorbance of $\left(\mathrm{Au}^{0} \mathrm{CN}\right)_{\mathrm{ad}}^{-}$intermediates on the electrode. [51] 
Figure $1 \mathrm{~b}$ shows four CVs recorded using a Au layer deposited on the bottom side of a track-etched membrane with $10^{9}$ pores $/ \mathrm{cm}^{2}$ as working electrode. This Au backlayer on the membrane was prepared by sputtering of Au and electrodeposition of $\mathrm{Au}$ from a sulfide-based electrolyte (Metakem, $\mathrm{pH} 7.5$ ) at $-0.7 \mathrm{~V}$ in a two-electrode arrangement with a $\mathrm{Au}$ wire as anode. Figure $1 \mathrm{~b}$ displays the resulting CVs for the same three electrolytes as in Figure 1a. In addition, the green curve corresponds to a $\mathrm{CV}$ for an electrolyte consisting of $50 \mathrm{mM} \mathrm{KAu}(\mathrm{CN})_{2}$ and $20 \mathrm{mM} \mathrm{KAg}(\mathrm{CN})_{2}$. For the $\mathrm{CV}$ of $\mathrm{Au}$ we find the diffusion limited peak at $-1.2 \mathrm{~V}$, this means at a slightly lower (less negative) potential than for the macroelectrode. This small shift to lower (less negative) potentials is also observed for the additional plateau at around $-0.67 \mathrm{~V}$ in the $\mathrm{CV}$ of $\mathrm{Au}$ and can explained by the altered mass transport between a macroscopic rod-shaped electrode and the recessed electrode geometry. For the Ag electrolyte, we find a reduction peak at $-0.68 \mathrm{~V}$ and a further current increase at higher (more negative) potential. Both, might be related to the deposition of $\mathrm{Ag}(\mathrm{CN})_{2}^{-}$ ions and additional $\mathrm{Au}(\mathrm{CN})_{2}^{-}$ions, originating from the $\mathrm{Au}$ backlayer as in the case of the macroelectrode. It is obvious that $\mathrm{Ag}(\mathrm{CN})_{2}^{-}$ions are reduced at lower potential than $\mathrm{Au}(\mathrm{CN})_{2}^{-}$ ions, which is in accordance with the result for the macroelectrode. We find that the deposition in the membrane of Au starts at about $-0.4 \mathrm{~V}$ and for $\mathrm{Ag}$ at about $-0.2 \mathrm{~V}$. In addition, the $\mathrm{CV}$ of the mixed AuAg electrolyte shows, similar to the $\mathrm{CV}$ for the $\mathrm{Ag}$ electrolyte, a plateau at about $-0.7 \mathrm{~V}$ followed by a further current increase. The current flow is much higher due to the higher concentration of the electrolyte.

Based on these CVs, we suggest that Ag-rich nanowires can be electrodeposited with a slow rate, as needed for a well-controlled process, at low potentials close to $-0.5 \mathrm{~V}$. To grow Au-rich nanowires higher negative potentials need to be applied. The concentration of $\operatorname{KAu}(\mathrm{CN})_{2}$ in the electrolyte is increased compared to the $\mathrm{KAg}(\mathrm{CN})_{2}$ concentration to counteract the co-deposition of $\mathrm{Ag}$ at these more negative potentials.

To investigate the composition of AuAg alloy nanowires as a function of the deposition voltage, we deposited nanowire arrays at three different voltages, namely $-0.5 \mathrm{~V},-0.8 \mathrm{~V}$, and $-1.1 \mathrm{~V}$ using an electrolyte containing $20 \mathrm{mM} \mathrm{KAg}(\mathrm{CN})_{2}$ and $50 \mathrm{mM} \mathrm{KAu}(\mathrm{CN})_{2}$. The corresponding potentiostatic deposition curves at the three different voltages are shown in Supporting Information File 1 in Figure S2 together with the deposition curves using a second electrolyte with an identical $\mathrm{Au}$ and $\mathrm{Ag}$ ratio in the electrolyte. Afterwards we dissolved the polymer membrane, and transferred the wires onto TEM grids (Plano). EDX-in-SEM spectra were measured on bundles of the resulting wires. Extracts of the obtained EDX spectra are shown in Figure 1c, depicting the L $\alpha$ peak $(2.984 \mathrm{keV})$ and the $\mathrm{M} \alpha$ peak of $\mathrm{Au}(2.120 \mathrm{keV})$. All spectra are normalized to the height of the M $\alpha$ peak of Au. The quantitative analysis reveals for the nanowires deposited at $-1.1 \mathrm{~V}$ (green line), $-0.8 \mathrm{~V}$ (black line), and $-0.5 \mathrm{~V}$ (red line) compositions of about $\mathrm{Au}_{60} \mathrm{Ag}_{40}, \mathrm{Au}_{40} \mathrm{Ag}_{60}$, and $\mathrm{Au}_{15} \mathrm{Ag}_{85}$, respectively. This demonstrates that it is possible to vary the AuAg composition in the wires in a controlled manner only by varying the potential within $0.6 \mathrm{~V}$.

We applied these results to fabricate segmented Au-rich/Agrich/Au-rich nanowires with tailored composition along its axis using pulsed deposition. We choose for the synthesis a deposition voltage of $U_{1}=-1.1 \mathrm{~V}$ for the Au-rich segments, and $U_{2}=-0.5 \mathrm{~V}$ to create a Ag-rich middle segment. Figure $2 \mathrm{a}$ shows two representative pulse sequences together with the

(a)

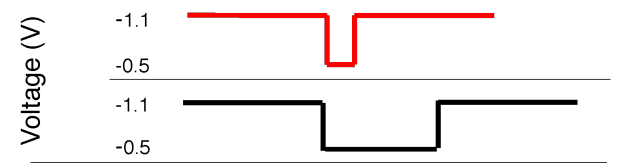

(b)
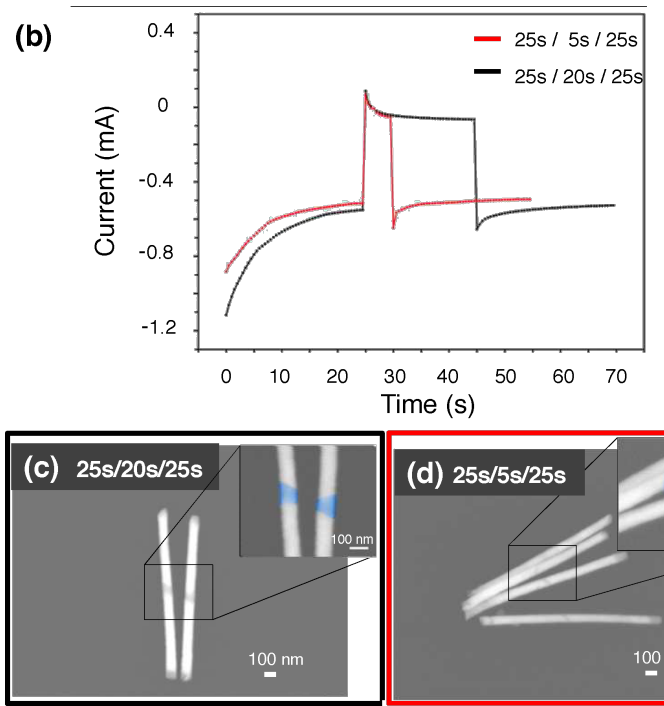

(d) $25 \mathrm{~s} / 5 \mathrm{~s} / 25 \mathrm{~s}$

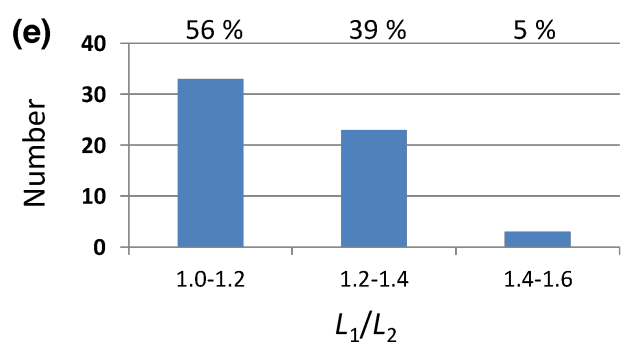

Figure 2: (a) Two pulse sequences applied for the electrodeposition of two arrays of segmented nanowires. The duration of the first and the third pulse is hold constant at $25 \mathrm{~s}$, while the duration of the middle pulse is in the black curve $20 \mathrm{~s}$ and in the red curve $5 \mathrm{~s}$ and (b) corresponding current-versus-times curves recorded during the deposition of the nanowires. (c) and (d) SEM images of the resulting segmented wires. Image (c) corresponds to the middle pulse of $20 \mathrm{~s}$ and (d) to a pulse of $5 \mathrm{~s}$. (e) Histogram displaying the distribution of the ratio between the length of the two Au-rich segments of the wires. 
corresponding current-vs-time curves in Figure 2b. During the first and third pulse $U_{1}$ is applied. Both pulses have the same duration, in this case $25 \mathrm{~s}$. In between these two pulses the voltage is switched to $U_{2}$. The duration of this second pulse is $5 \mathrm{~s}$ and $20 \mathrm{~s}$ for the red and the black curves, respectively.

The current-vs-time curves display a strong decrease of the absolute value of the current over about $20 \mathrm{~s}$. After that, a constant cathodic current value is approached for the last five seconds of the first pulse. The decrease is due to the reduction of ions in the vicinity of the cathode and the formation of a depletion zone growing into the bulk solution. An approximately constant current is flowing during the growth of cylindrical wires. When the voltage is switched to $U_{2}$ an immediate change to an anodic current is recorded, followed by a further decrease of the absolute current value to a constant small cathodic current. The anodic current is attributed to the capacitance effect $[52,53]$ as well as to exchange displacement, which takes place since the oxidation of $\mathrm{Au}$ atoms occurs at similar potentials as the reduction of the $\operatorname{Ag}(\mathrm{CN})_{2}^{-}$ions as it can be seen in the $\mathrm{CV}$ in Figure $1 \mathrm{~b}$. Once enough $\mathrm{Ag}(\mathrm{CN})_{2}^{-}$ions are reduced, the dissolution of $\mathrm{Au}$ atoms is most probably suppressed, resulting in a constant current flow, during the growth of the Ag-rich segments. When the voltage is switched back to $-1.1 \mathrm{~V}$, the current decreases rapidly again to a high negative value, followed by a slight increase up to a constant value, which is approximately the same as for the first pulse. We measure a slight difference between the current values for the two membranes that we attribute to small differences in the number of channels and in the filling rate. A similar shape of the current-vs-time curves has previously been reported for the growth of segmented $\mathrm{CuCo}$ nanowires in anodized alumina templates $[31,53,54]$.

The SEM images in Figure 2c and Figure 2d visualize the segmented nanowires resulting from the deposition process in Figure 2a and Figure 2b. The length of the middle pulse is reduced from $20 \mathrm{~s}$ (Figure 2c) to $5 \mathrm{~s}$ (Figure 2d). The three different segments with relatively sharp interfaces are displayed by using backscattered electrons. In the details of the figure the Ag-rich segments are coloured in blue to better distinguish them from the Au-rich segments. As expected, the representative SEM images reveal a smaller Ag-rich segment for the short $5 \mathrm{~s}$ middle pulse (d), than for the pulse with duration $20 \mathrm{~s}$ (c). Figure S3 in the supporting information shows a TEM image and a high-resolution TEM image of one of the wires corresponding to the same array as the wires in Figure $2 d$. The figure reveals the polycrystalline structure of our wires. To investigate the symmetry of the created nanostructures, the histogram in Figure $2 \mathrm{e}$ shows for about 60 nanowires the ratio between the lengths $L_{1}$ and $L_{2}$ of the two Au-rich segments corresponding to one segmented wire. The histogram shows that $56 \%$ of the wires exhibit a length ratio between 1.0 and 1.2. Very unsymmetrical structures having a ratio higher than 1.4 are rarely observed. The average length of both Au-rich segments was estimated to be $700 \pm 100 \mathrm{~nm}$.

Figure $3 \mathrm{a}-\mathrm{c}$ show SEM images of bundles of nanowires deposited with a similar three-pulse sequence as in Figure 2a. Compared to Figure 2, the length of the pulse at $-1.1 \mathrm{~V}$ is increased to $37 \mathrm{~s}$. The length of the middle pulse at $U=-0.5 \mathrm{~V}$ is in (a) $25 \mathrm{~s}$, in (b) $18 \mathrm{~s}$ and in (c) $10 \mathrm{~s}$. The figure visualizes that the Au-rich segments are longer compared to the segments in Figure 2. Analysing 26 wires, the average length of both Au-rich segments was estimated to be $1000 \pm 100 \mathrm{~nm}$ and $65 \%$ of the wires reveal a length ratio between 1.0 and 1.2. In agreement with the results shown previously in Figure 2, Figure 3a-c evidences again that the length of the Ag-rich segment is controlled by the pulse duration. Figure $3 d$ displays an EDX-inSEM scan along one of the nanowires corresponding to a sample prepared from a pulse sequence of $37 \mathrm{~s}$ at $-1.1 \mathrm{~V}$ and 12 $\mathrm{s}$ at $-0.5 \mathrm{~V}$. The Ag L $\alpha$ line, revealing increased count rates at the position of the dark segment in the middle of the wire, confirms position and length of the Ag-rich segment.

To investigate the segment length of the Ag-rich segments as a function of the pulse duration, we determined the length of 15-30 segments for different samples by SEM analysis (Figure 4a). Blue and red symbols distinguish between samples with pulse duration of $25 \mathrm{~s}$ (blue) and $37 \mathrm{~s}$ (red) for the Au-rich segment, respectively. The black symbols are the mean value from the measured segment length with standard deviation. The length of each Ag-rich segment is defined as the shortest distance between two Au-rich segments. The determination of the length distribution is challenging due to the different crystal orientations. In addition, only few selected wires could be measured for each sample. As expected, the mean value becomes larger with increasing deposition time, independent of the pulse length of the Au-rich segments. Figure $4 \mathrm{~b}$ depicts the distribution width, represented by the standard deviation, versus the average value of the Ag-rich segment length. The increase in distribution width is evident. Similar behaviour is also observed for the electrodeposition of thin films where the effect is called kinetic surface roughening [55,56].

These $\mathrm{Au} / \mathrm{Ag} / \mathrm{Au}$ nanowires constitute excellent platforms for the fabrication of small nanogaps, by selective dissolution of the Ag segment. The method named "on-wire lithography" has been reported previously for wires of different noble metals [38]. In these cases, segmented nanowires were created by using different electrolytes for $\mathrm{Au}$ and $\mathrm{Ag}$ and by exchanging the electrolyte after the deposition of each segment. Our nano- 


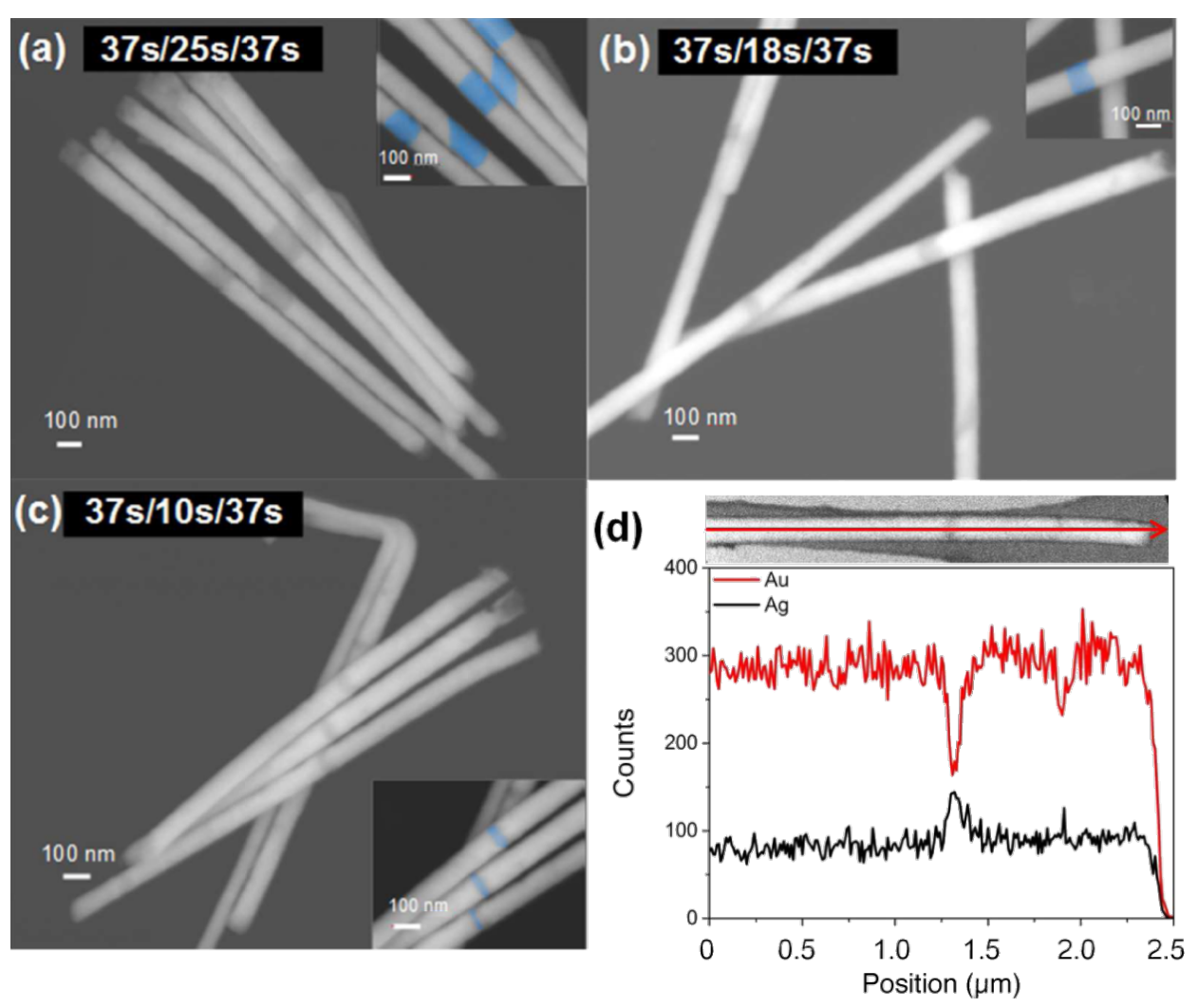

Figure 3: SEM images of $\mathrm{Au}_{60} \mathrm{Ag}_{40} / \mathrm{Au}_{15} \mathrm{Ag}_{85} / \mathrm{Au}_{60} \mathrm{Ag}_{40}$ nanowires similar to Figure 2 . The length of the middle pulse is decreased form $25 \mathrm{~s}$ (a), to $18 \mathrm{~s}(\mathrm{~b})$ and $10 \mathrm{~s}$ (c). In the insets the Ag-rich segments are marked in blue. (d) EDX scan along a segmented nanowire. The segmented wire is shown in the SEM image on top of the scan. The red and black lines depict the count numbers measured for the Au-Ma peak and for the Ag-La peak, respectively.

wires, in turn, are deposited from a single-bath electrolyte, which could influence the dissolution process and thus the morphology of the resulting gaps. Selective dissolution of the Ag-rich segments results in well-controllable gaps.

Figure 5 displays SEM images of the same two wires with diameters of about $65 \mathrm{~nm}$ consisting of six Au-rich and six Ag-rich segments (a) before and (b) after the nitric acid treatment. For dissolution, the wires deposited on a Si wafer were immersed for three hours into concentrated nitric acid and subsequently cleaned with deionized water. It is remarkable that the nanowires are not displaced during the nitric acid treatment. This is very important for the preparation of defined gap sizes and it furthermore enables implementation of this preparation method at larger scale applications, for example, using wellaligned arrays of nanostructures.

The insets of Figure 5a and Figure 5b clearly confirm that exclusively the Ag-rich segments are dissolved, while Au-rich segments remain intact. We find that two of the ten Ag-rich segments are completely transferred into nanogaps, while for the others, small junctions connecting two segments are visible. For some of them, it is very difficult to decide if a gap is created or if metal connects two segments. We think that the connections are due to the small amount of Au that was initially in the Ag-rich segment. The gaps found in Figure 2 have sizes of about 30 and $15 \mathrm{~nm}$. The smallest gaps that we were able to create from samples with a duration of the middle pulse of $10 \mathrm{~s}$ had sizes of about 5 to $10 \mathrm{~nm}$. Exemplarily, a TEM and a STEM in SEM image of such small gaps are shown in Figure S4 of Supporting Information File 1.

It is interesting that the morphology of the Au-rich segments is maintained, although they contain a considerable amount of Ag. By EDX analysis, we find that the Ag content in these segments is not changed through the nitric acid treatment. This effect is ascribed to dealloying in AuAg alloy structures taking place through layer-by-layer dissolution of Ag atoms and diffusion of $\mathrm{Au}$ atoms onto the surface [57,58]. Due to a higher $\mathrm{Au}$ concentration in the Au-rich segments, a Au passivation layer on the surface is quickly formed, prohibiting changes of morphology and composition. This agrees with results in [59], where morphology changes of nitric acid treated $\mathrm{Au}_{x} \mathrm{Ag}_{1-x}$ is only found for a gold content of $x \leq 40$. 
(a)

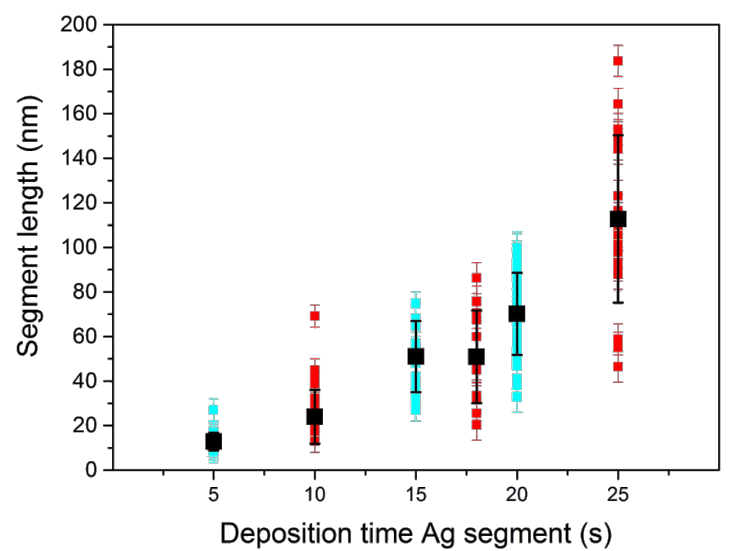

(b)

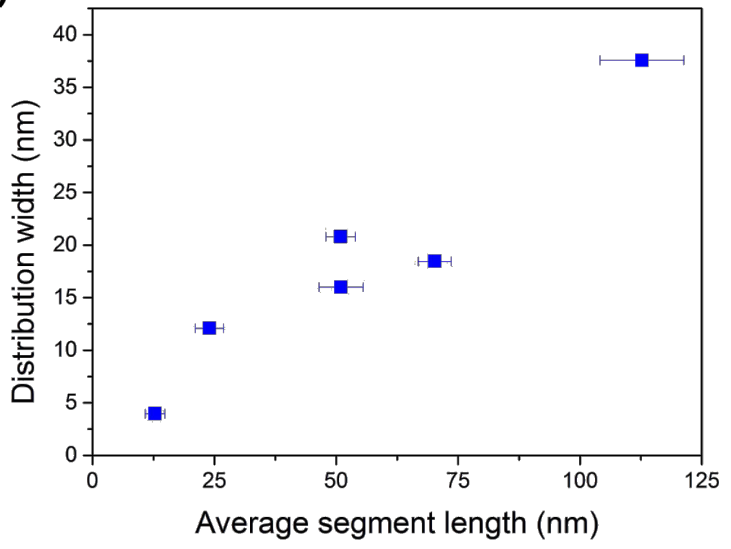

Figure 4: (a) Segment length of the silver segment versus pulse length for wires corresponding to six different nanowire arrays. Cyan blue values correspond to arrays with $25 \mathrm{~s}$ deposition time for the Au-rich segments, red values to $37 \mathrm{~s}$ deposition time. The black values reveal the average value for each array with its standard deviation. (b) Distribution width given by the standard deviation for the silver segments versus average value of segment length.

In addition, we studied how moderate annealing influences shape and size of the gaps formed during the nitric acid treatment. The nanogaps were therefore annealed at $300{ }^{\circ} \mathrm{C}$ for 30 min with a heating rate of $9{ }^{\circ} \mathrm{C} / \mathrm{min}$. After the annealing process, seven nanogaps are visible in Figure $5 \mathrm{c}$. This means that by the influence of the annealing in several cases the small junctions, connecting two Au-rich segments, could be removed. The ends of the Au-rich segments are rounded compared to the unheated segments and the gap sizes are in most of the cases increased. Rounding of the nanowire ends and removal of small bridges can be explained by surface diffusions of the atoms and the lower surface energy of spherical surfaces compared to cylindrical structures [60].

\section{Conclusion}

In conclusion, we demonstrated the electrodeposition of segmented AuAg alloy nanowires with controlled dimensions by
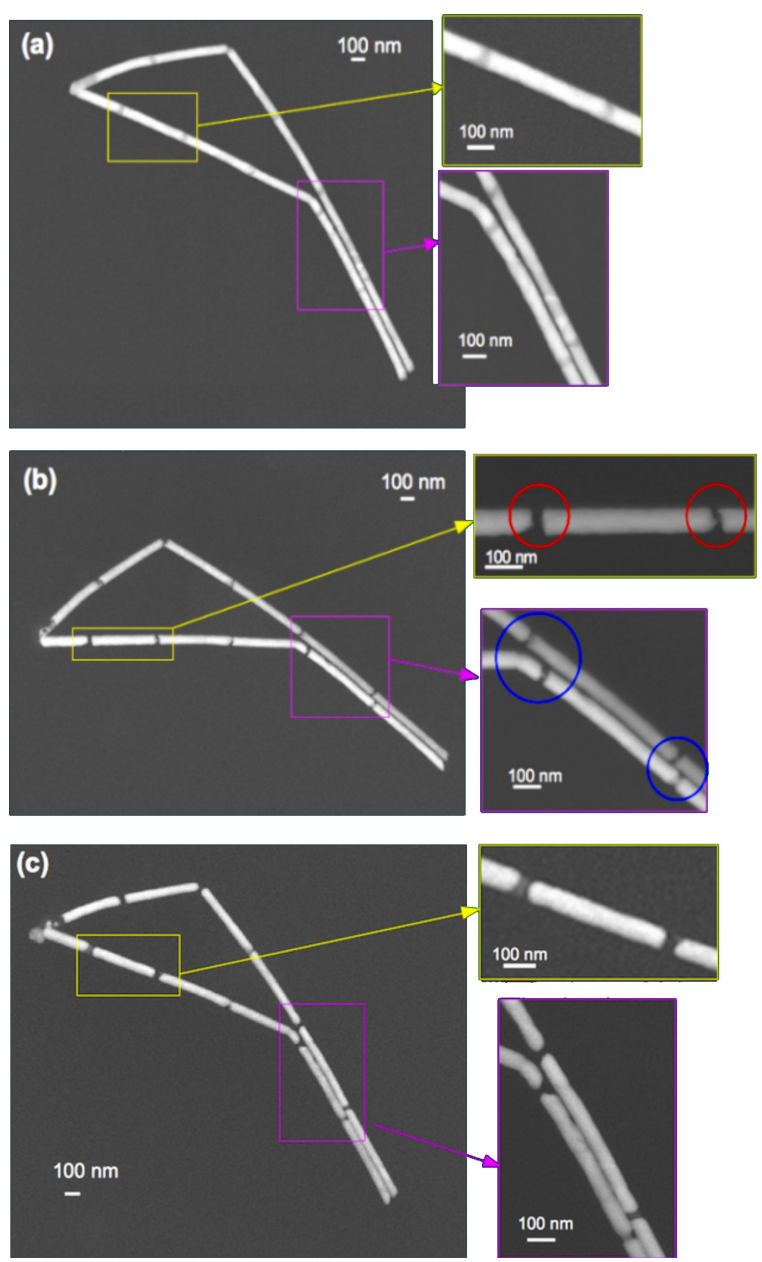

Figure 5: (a) SEM image of two segmented nanowires obtained from a pulse sequence of 6 pulses at $-1.1 \mathrm{~V}$ for $25 \mathrm{~s}$ and 6 pulses at $-0.5 \mathrm{~V}$ with a duration of $15 \mathrm{~s}$. (b) The same two nanowires after treatment with nitric acid. (c) Nanowires after nitric acid treatment and annealing at $300{ }^{\circ} \mathrm{C}$ for $30 \mathrm{~min}$.

pulsed electrochemical deposition. The Au:Ag concentration is governed by the electrolyte and by the voltage applied during deposition. Cyclic voltammetry of $\mathrm{Au}$ and $\mathrm{Ag}$ deposition in iontrack etched membranes reveals that the current onset for deposition of Ag occurs at lower potentials than of Au. The fabrication of Ag-rich segments thus requires lower potentials than Au-rich segments. The length of $\mathrm{Au}$ - and the Ag-rich segments is controlled by the pulse duration. By dissolving Ag-rich segments deposited between two Au-rich segments, nanowires separated by small gaps are created. This method has previously been reported for segmented nanowires prepared by potentiostatic deposition and by exchanging the electrolyte after each segment. The process is termed on-wire lithography [38]. We have tested if this method is also applicable to our segmented wires prepared by pulsed deposition. We find that the characteristics such as gap sizes and shapes are defined by the Au- and Ag-rich segments. However, only a small number of Ag-rich 
segments are transformed into gaps. For the majority of the segments, small metallic interconnects remain between the segments. We attribute this to the small amount of $\mathrm{Au}$ atoms that are present in the Ag-rich segments. The process has been improved by annealing the wires to moderate temperatures. This allows one to increase the number of created gaps, and also modifies the shape of the remaining segments to more rounded ends. These nanowires separated by small gaps or connected by small junction are excellent candidates as model systems for plasmonic characterizations with EELSTEM $[45,61]$ and surface enhanced infrared spectroscopy measurements.

\section{Supporting Information}

\section{Supporting Information File 1}

Supporting Information shows additional figures on the electrodeposition of segmented nanowires and gaps. Figure S1 depicts a typical ion-track membrane. Figure S2 shows the electrodeposition curves for two different electrolytes together with EDX results of the wires. Figure S3 shows TEM analysis of a segmented nanowire and Figure S4 presents TEM and SEM images of small nanogaps.

[http://www.beilstein-journals.org/bjnano/content/ supplementary/2190-4286-6-131-S1.pdf]

\section{Acknowledgements}

The authors thank W. Sigle for TEM analysis of the segmented wires.

\section{References}

1. Piraux, L.; George, J.; Despres, J.; Leroy, C.; Ferain, E.; Legras, R.; Ounadjela, K.; Fert, A. Appl. Phys. Lett. 1994, 65, 2484-2486. doi:10.1063/1.112672

2. Liu, K.; Nagodawithana, K.; Searson, P. C.; Chien, C. L. Phys. Rev. B 1995, 51, 7381-7384. doi:10.1103/PhysRevB.51.7381

3. Bentley, A. K.; Trethewey, J. S.; Ellis, A. B.; Crone, W. C. Nano Lett. 2004, 4, 487-490. doi:10.1021/nl035086j

4. Mock, J. J.; Oldenburg, S. J.; Smith, D. R.; Schultz, D. A.; Schultz, S. Nano Lett. 2002, 2, 465-469. doi:10.1021/n10255247

5. Zhu, J. Nanoscale Res. Lett. 2009, 4, 977-981. doi:10.1007/s11671-009-9344-4

6. Goldberger, J.; He, R.; Zhang, Y.; Lee, S.; Yan, H.; Choi, H.-J.; Yang, P. Nature 2003, 422, 599-602. doi:10.1038/nature01551

7. Keating, C. D.; Natan, M. J. Adv. Mater. 2003, 15, 451-454. doi:10.1002/adma.200390105

8. Nicewarner-Peña, S. R.; Carado, A. J.; Shale, K. E.; Keating, C. D. J. Phys. Chem. B 2003, 107, 7360-7367. doi:10.1021/jp034139i

9. Zhang, D.; Liu, Z.; Han, S.; Li, C.; Lei, B.; Stewart, M. P.; Tour, J. M.; Zhou, C. Nano Lett. 2004, 4, 2151-2155. doi:10.1021/nl048758u
10. Chong, Y. T.; Görlitz, D.; Martens, S.; Yau, M. Y. E.; Allende, S.; Bachmann, J.; Nielsch, K. Adv. Mater. 2010, 22, 2435-2439. doi:10.1002/adma.200904321

11. Herderick, E. D.; Tresback, J. S.; Vasiliev, A. L.; Padture, N. P. Nanotechnology 2007, 18, 319001. doi:10.1088/0957-4484/18/31/319001

12. Lauhon, L. J.; Gudiksen, M. S.; Wang, D.; Lieber, C. M. Nature 2002, 420, 57-61. doi:10.1038/nature01141

13. Law, M.; Greene, L. E.; Radenovic, A.; Kuykendall, T.; Liphardt, J.; Yang, P. J. Phys. Chem. B 2006, 110, 22652-22663. doi:10.1021/jp0648644

14. Greene, L. E.; Law, M.; Yuhas, B. D.; Yang, P. J. Phys. Chem. C 2007, 111, 18451-18456. doi:10.1021/jp077593।

15. Czaban, J. A.; Thompson, D. A.; LaPierre, R. R. Nano Lett. 2008, 9 , 148-154. doi:10.1021/nl802700u

16. Trautmann, C. Micro-and nanoengineering with ion tracks. In Ion Beams in Nanoscience and Technology; Hellborg, R.; Whitlow, H. J.; Zhang, Y., Eds.; Springer: Berlin, Germany, 2010; pp 369-387. doi:10.1007/978-3-642-00623-4_30

17. Toimil-Molares, M. E. Beilstein J. Nanotechnol. 2012, 3, 860-883. doi:10.3762/bjnano.3.97

18. Picht, O.; Müller, S.; Alber, I.; Rauber, M.; Lensch-Falk, J.; Medlin, D. L.; Neumann, R.; Toimil-Molares, M. E. J. Phys. Chem. C 2012, 116, 5367-5375. doi:10.1021/jp210491g

19. Müller, S.; Schötz, C.; Picht, O.; Sigle, W.; Kopold, P.; Rauber, M.; Alber, I.; Neumann, R.; Toimil-Molares, M. E. Cryst. Growth Des. 2012, 12, 615-621. doi:10.1021/cg200685c

20. Schubert, I.; Sigle, W.; Burr, L.; van Aken, P.; Trautmann, C.; Toimil-Molares, M. Adv. Mater. Lett. 2015, 6, 377-382. doi:10.5185/amlett.2015.5721

21. Wang, L.; Yu-Zhang, K.; Metrot, A.; Bonhomme, P.; Troyon, M. Thin Solid Films 1996, 288, 86-89. doi:10.1016/S0040-6090(96)08791-3

22. Hernández, R. M.; Richter, L.; Semancik, S.; Stranick, S.; Mallouk, T. E. Chem. Mater. 2004, 16, 3431-3438. doi:10.1021/cm0496265

23. Chakarvarti, S. K.; Vetter, J. J. Micromech. Microeng. 1993, 3, 57. doi:10.1088/0960-1317/3/2/004

24. Valizadeh, S.; Hultman, L.; George, J. M.; Leisner, P. Adv. Funct. Mater. 2002, 12, 766-772. doi:10.1002/adfm.200290005

25. Wang, A. A.; Lee, J.; Jenikova, G.; Mulchandani, A.; Myung, N. V.; Chen, W. Nanotechnology 2006, 17, 3375. doi:10.1088/0957-4484/17/14/006

26. Van Hoang, N.; Kumar, S.; Kim, G.-H. Nanotechnology 2009, 20, 125607. doi:10.1088/0957-4484/20/12/125607

27. Burdick, J.; Alonas, E.; Huang, H.-C.; Rege, K.; Wang, J. Nanotechnology 2009, 20, 065306. doi:10.1088/0957-4484/20/6/065306

28. Chen, M.; Chien, C.-L.; Searson, P. C. Chem. Mater. 2006, 18, 1595-1601. doi:10.1021/cm052262b

29. Cho, J. U.; Wu, J.-H.; Min, J. H.; Lee, J. H.; Liu, H.-L.; Kim, Y. K. J. Magn. Magn. Mater. 2007, 310, 2420-2422. doi:10.1016/j.jmmm.2006.10.809

30. Lee, J. H.; Wu, J. H.; Liu, H. L.; Cho, J. U.; Cho, M. K.; An, B. H.; Min, J. H.; Noh, S. J.; Kim, Y. K. Angew. Chem., Int. Ed. 2007, 46, 3663-3667. doi:10.1002/anie.200605136

31. Fedorov, F. S.; Mönch, I.; Mickel, C.; Tschulik, K.; Zhao, B.; Uhlemann, M.; Gebert, A.; Eckert, J. J. Electrochem. Soc. 2013, 160, D13-D19. doi:10.1149/2.006302jes 
32. Choi, J.-r.; Oh, S. J.; Ju, H.; Cheon, J. Nano Lett. 2005, 5, 2179-2183. doi:10.1021/nl051190k

33. Wang, J. J. Mater. Chem. 2008, 18, 4017-4020. doi:10.1039/B803807D

34. Hunyadi, S. E.; Murphy, C. J. J. Mater. Chem. 2006, 16, 3929-3935. doi:10.1039/B607116C

35. Lee, K.-S.; El-Sayed, M. A. J. Phys. Chem. B 2006, 110, 19220-19225. doi:10.1021/jp062536y

36. Liu, M.; Guyot-Sionnest, P. J. Phys. Chem. B 2004, 108, 5882-5888. doi:10.1021/jp037644o

37. Nicewarner-Peña, S. R.; Freeman, R. G.; Reiss, B. D.; He, L.; Peña, D. J.; Walton, I. D.; Cromer, R.; Keating, C. D.; Natan, M. J. Science 2001, 294, 137-141. doi:10.1126/science.294.5540.137

38. Qin, L.; Park, S.; Huang, L.; Mirkin, C. A. Science 2005, 309, 113-115. doi:10.1126/science.1112666

39. Osberg, K. D.; Schmucker, A. L.; Senesi, A. J.; Mirkin, C. A. Nano Lett. 2011, 11, 820-824. doi:10.1021/nl1041534

40.Zhou, X.; Shade, C. M.; Schmucker, A. L.; Brown, K. A.; He, S.; Boey, F.; Ma, J.; Zhang, H.; Mirkin, C. A. Nano Lett. 2012, 12, 4734-4737. doi:10.1021/nl302171z

41. Qin, L.; Zou, S.; Xue, C.; Atkinson, A.; Schatz, G. C.; Mirkin, C. A. Proc. Natl. Acad. Sci. U. S. A. 2006, 103, 13300-13303. doi:10.1073/pnas.0605889103

42. Wei, W.; Li, S.; Qin, L.; Xue, C.; Millstone, J. E.; Xu, X.; Schatz, G. C.; Mirkin, C. A. Nano Lett. 2008, 8, 3446-3449. doi:10.1021/nl8023164

43. Osberg, K. D.; Rycenga, M.; Harris, N.; Schmucker, A. L.; Langille, M. R.; Schatz, G. C.; Mirkin, C. A. Nano Lett. 2012, 12, 3828-3832. doi:10.1021/nl301793k

44. Chen, X.; Guo, Z.; Yang, G.-M.; Li, J.; Li, M.-Q.; Liu, J.-H.; Huang, X.-J. Mater. Today 2010, 13, 28-41. doi:10.1016/S1369-7021(10)70201-7

45. Alber, I.; Sigle, W.; Müller, S.; Neumann, R.; Picht, O.; Rauber, M.; van Aken, P. A.; Toimil-Molares, M. E. ACS Nano 2011, 5, 9845-9853. doi:10.1021/nn2035044

46. Osberg, K. D.; Harris, N.; Ozel, T.; Ku, J. C.; Schatz, G. C.; Mirkin, C. A. Nano Lett. 2014, 14, 6949-6954. doi:10.1021/nl503207j

47. Smith, P. A.; Nordquist, C. D.; Jackson, T. N.; Mayer, T. S.; Martin, B. R.; Mbindyo, J.; Mallouk, T. E. Appl. Phys. Lett. 2000, 77, 1399-1401. doi:10.1063/1.1290272

48. Liu, S.; Tok, J. B.-H.; Bao, Z. Nano Lett. 2005, 5, 1071-1076. doi:10.1021/nl050581w

49. Uran, C.; Unal, E.; Kizil, R.; Demir, H. V. IEEE J. Quantum Electron. 2009, 15, 1413-1419. doi:10.1109/JSTQE.2009.2020057

50. Trautmann, C. Nucl. Instrum. Methods Phys. Res., Sect. B 1995, 105 , 81-85. doi:10.1016/0168-583X(95)00555-2

51. Ji, C.; Oskam, G.; Ding, Y.; Erlebacher, J. D.; Wagner, A. J.; Searson, P. C. J. Electrochem. Soc. 2003, 150, C523-C528. doi:10.1149/1.1585053

52. Ghosh, S. K.; Grover, A. K.; Chowdhury, P.; Gupta, S. K.; Ravikumar, G.; Aswal, D. K.; Kumar, M. S.; Dusane, R. O. Appl. Phys. Lett. 2006, 89, 132507. doi:10.1063/1.2357014

53. Ghosh, S. K. Electrochim. Acta 2008, 53, 8070-8077. doi:10.1016/j.electacta.2008.06.019

54. Uhlemann, M.; Gebert, A.; Herrich, M.; Krause, A.; Cziraki, A.; Schultz, L. Electrochim. Acta 2003, 48, 3005-3011. doi:10.1016/S0013-4686(03)00366-9

55. Huo, S.; Schwarzacher, W. Phys. Rev. Lett. 2001, 86, 256. doi:10.1103/PhysRevLett.86.256

56. Hasan, N. M.; Mallett, J. J.; dos Santos Filho, S. G.; Pasa, A. A.; Schwarzacher, W. Phys. Rev. B 2003, 67, 081401. doi:10.1103/PhysRevB.67.081401
57. Erlebacher, J.; Aziz, M. J.; Karma, A.; Dimitrov, N.; Sieradzki, K. Nature 2001, 410, 450-453. doi:10.1038/35068529

58. Erlebacher, J.; Seshadri, R. MRS Bull. 2009, 34, 561-568. doi:10.1557/mrs2009.155

59. Ji, C.; Searson, P. C. Appl. Phys. Lett. 2002, 81, 4437-4439. doi:10.1063/1.1526920

60. Nichols, F. A. J. Mater. Sci. 1976, 11, 1077-1082. doi:10.1007/BF00553115

61. Alber, I.; Sigle, W.; Demming-Janssen, F.; Neumann, R.; Trautmann, C.; van Aken, P. A.; Toimil-Molares, M. E. ACS Nano 2012, 6, 9711-9717. doi:10.1021/nn303149p

\section{License and Terms}

This is an Open Access article under the terms of the Creative Commons Attribution License

(http://creativecommons.org/licenses/by/2.0), which permits unrestricted use, distribution, and reproduction in any medium, provided the original work is properly cited.

The license is subject to the Beilstein Journal of

Nanotechnology terms and conditions:

(http://www.beilstein-journals.org/bjnano)

The definitive version of this article is the electronic one which can be found at: doi:10.3762/bjnano.6.131 